\title{
Exploring online fitness culture and young females
}

While previous studies have investigated online health communities and health seeking behaviours, less attention has been directed at the growing impact of the online fitness movement. This paper draws on the concept of biopedagogies to examine the messages transmitted within fitness culture on social networking sites (SNSs), and their role as a channel for health and fitness information. To explore this, a multi-method approach was conducted. The two methods included a netnography (online ethnography) and 22 semi-structured individual interviews with female participants aged 18 to 24 in Australia. The study suggests that online fitness use is becoming a popular leisure activity and source of health and fitness information. It reveals how SNSs are used as a platform to gather and teach ideas of health and fitness, and the manner in which textual and photographic online communication facilitates the social construction and transmission of this knowledge. Results indicated that although fitness accounts on SNSs offer differing notions to present alternative and competing realities, users predominantly chose to follow the normalised and dominant health discourses. Noteworthy, the onus is firmly placed on the individual within these health and fitness messages to adhere to norms of correct health practices and choices. This has connotations relevant to eHealth literacy.

Keywords: social networking sites; biopedagogies; health information; fitness; eHealth literacy

\section{Introduction}

There has been a cultural shift towards the use of the Internet as a mode of seeking information and communicating about health (Berkman, Davis, \& McCormack, 2010; Hesse \& Shneiderman, 2007). People seek health information to 'reduce uncertainty regarding health status' and to 'construct a social and personal (cognitive) sense of health' (Tardy \& Hale, 1998, p. 338). The Internet can help with this by providing the advantages of up-to-date and available information (Feng \& Xie, 2015), social interaction (Toseeb \& Inkster, 2015), consumer autonomy and anonymity (DuttaBergman, 2004) and information tailoring (Cline \& Haynes, 2001). Studies have shown 
that the information found online is highly trusted, with young people modifying their behaviour on the basis of the information gathered (Ettel et al., 2012). Health information is defined as 'any information which is related to the practice of medicine and healthcare' (Cullen, 2006, p. 1). In the context of this paper, fitness and diet are subsets of health, with studies inextricably linking these notions (Szabo, 2003; Wright \& Halse, 2014).

The rapid adoption of SNSs such as Facebook and Instagram, as a way of communication, has resulted in SNSs becoming a pervasive means of sourcing information about health for young adults (Feng \& Xie, 2015; Oh, Lauckner, Boehmer, Fewins-Bliss, \& Li, 2013). Vaterlaus et al., (2015) suggest that social media is a relevant factor in influencing a persons' health behaviour. Other research on the influence of using online information from health communities (see Camerini, Diviani, \& Tardini, 2010; Welbourne, Blanchard, \& Wadsworth, 2013) found that the primary use of these groups was to support people with communicable and non-communicable diseases (Coulson, Buchanan, \& Aubeeluck, 2007; Coulson \& Knibb, 2007) and people with mental health disorders (Buchanan \& Coulson, 2007; Toseeb \& Inkster, 2015). Significantly, it is the link between the influence of peers and SNSs' interactive nature, that emphasizes the impact on health behaviours (McFerran, Dahl, Fitzsimons, \& Morales, 2010). While research has indicated that the Internet does not replace the role of trusted health professionals, or peers and adults (Percheski \& Hargittai, 2011), the Internet has provided a forum helping to provide and disseminate health information. Using these SNSs is a popular leisure activity for young Australian people (Australian Bureau of Statistics, 2012; Sensis, 2014). Although a sedentary activity (Kerner, 2005), it also has a bearing on other leisure time activity, for example, physical activity. Previous research about online fitness has looked at fitspiration (an 
amalgamation of the words fitness and inspiration) images from Instagram (Tiggemann \& Zaccardo, 2015), body perceptions in a bodybuilding community (2012), and gender and the body in the 'blogosphere' (Andreasson \& Johansson, 2013b, 2013c). Despite this, few studies have explored the fitness movement on SNSs, and more specifically, young females' experiences of using it as a means to gather health information.

This paper explores this practice, and how this process has the capacity to teach and inform online users' ideas of health and healthy practices. It presents a new perspective on gathering health information and allows a better understanding of online health information seekers' needs. Furthermore, it highlights vital improvements that can be made to information assessment, and quality.

\section{SNSs and Online Health Information}

Drawing from the notion of 'User Generated Content' (Kaplan \& Haenlein, 2010), SNSs have paved the way for a change in the usual ways of 'production, distribution and consumption' of information (Meyers, 2012, p. 1022). SNSs differ from other media in terms of their immediacy, interactive nature, and active participation, providing a valuable insight into the popularity of messages posted. While health messages are circulated by users within the community, users also provide instant feedback through 'likes' (a thumbs up button pressed to express a person's liking of a picture, video or comment), and the transmission of these messages through 'sharing' a post. These developments have enabled rapid engagement and feedback of online health information, influencing leisure activity.

Previous research has examined the issues faced by consumers seeking health information online, with positive and negative implications (Cline \& Haynes, 2001; Rice \& Katz, 2001). Across the studies key factors have been noted, including concerns about the evaluation, credibility and accuracy of health information found using the 
Internet (Gray, Klein, Noyce, Sesselberg, \& Cantrill, 2005; Rice, 2006). Additionally, issues have been linked to difficulties comprehending information (Murero, D'Ancona, \& Karamanoukian, 2001), trustworthiness (Peterson, Aslani, \& Williams, 2003), and the feeling of being overwhelmed by information (Mcmillan \& Morrison, 2006; Velardo \& Drummond, 2013).

A SNS-based trend known as "thinspiration" (an amalgamation of the words thin and inspiration), or "pro-ana" (short for anorexia) showcase idealised images of emaciated people with additional text desired to motivate viewers' weight loss (Borzekowski, Schenk, Wilson, \& Peebles, 2010), and an eating-disorder lifestyle (Ghaznavi \& Taylor, 2015). The experience of using thinspiration SNSs accounts to gather health information has been shown to have negative effects on female users. These effects relate to self-esteem, appearance self-efficacy, body dissatisfaction and increased disordered eating variables (Harper, Sperry \& Thompson, 2008).

Additionally, viewers reported a greater likelihood of over exercising and thinking about their weight (Bardone-Cone \& Cass, 2007). These negative impacts are similar to that of exposure to unrealistically thin-ideal body types from traditional mass media (Groesz, Levine, \& Murnen, 2002; Hargreaves \& Tiggemann, 2003). Interestingly, Brotsky and Giles (2007) debate the idea that pro-ana sites encourage non-eating disordered people to become eating disordered. They found the most potentially problematic aspect of the sites to be the social interactions of the users.

A more recent SNS-based trend, labelled "fitspiration", is a hash-tag consisting of text and images of '...(people, photographs, skinny jeans, etc.) as inspiration to attain a fitness goal' (K-fig, 2011). Boepple and Thompson (2015) suggest a varied definition of fitspiration to include 'objectifying images of thin/muscular women and messages encouraging dieting and exercise for appearance, rather than health, motivated reasons' 
(p. 2). Recent research has found that although fitspiration images are inspirational in a number of ways, viewing fitspiration images resulted in negative consequences for body image and increased negative mood (Tiggemann \& Zaccardo, 2015). Many of the women in the fitspiration images are one particular body shape: toned, but also relatively thin. This promotes a visual health message through the platform of SNSs. The textual messages layered over the images also focus on appearance-related benefits of a 'healthy' lifestyle (Tiggemann \& Zaccardo, 2015). This links to research on exercise motivated by appearance rather than health, leisure, or enjoyment and is associated with negative body image (Strelan, Mehaffey, \& Tiggemann, 2003).

\section{Online Fitness Culture}

The hashtag fitspiration is commonly used within online fitness culture. It is important to understand that the concept of culture are unstable, transformative, and fluid 'worlds of meaning' (Kozinets, 2015). Following anthropological and sociological contested and shifting notions, culture is understood as a world of meaning, created by interacting individuals, where there is a 'momentary construction of common ground' (Amit \& Rapport, 2002, p. 11). Online fitness culture is created by a number of online communities that are focused on health and fitness. For example, these include general health, fitness, and bodybuilding communities on various SNSs, and wellbeing and healthy living blogs. Although their goals may be superficially diverse, the underlying messages circulated are general with a focus on the concepts of health and fitness. Specifically, attention is given to diet and food, inspiration, exercising, the body and weight, and representations of fit bodies (Andreasson \& Johansson, 2013a, 2013c; Smith \& Stewart, 2012). 
These underlying messages create unique 'practices, attitudes, modes of thought, and values' (Levy, 2001, p. xvi) that are circulated through online communications. This distinctive culture is developed and maintained through these communications (e.g. images, videos, comments). These are shared within the community by 'posting', 'liking', 'following', and 'sharing' information involving health and fitness.

\section{Biopedagogies}

Online fitness culture provides a platform where certain disciplinary and regulatory strategies (of health and the feminine body) are effectively promoted, an example of Wright's concept of biopedagogy. Wright (2009) conceptualises the term 'biopedagogies' as the 'disciplinary and regulatory strategies that enable the governing of bodies in the name of health and life' (p. 14). Biopedagogies can also be considered as describing the values and practices, disseminated and regulated within formal education (e.g. schools) and information education (e.g. media and the internet) (Wright \& Halse, 2014). These disseminated messages place 'individuals under constant surveillance', inclusive of self-regulation, through 'increasing their knowledge around "'obesity" related risks and 'instructing' them on how to eat healthily, and stay active' (Wright, 2009, p. 1, original emphasis).

As a "pedagogized society", the online fitness community utilise specific strategies in which knowledge is negotiated, produced and reproduced (Wright, 2009) and methods to evaluate and self-regulate the body are advocated (Iriart, Franco, \& Merhy, 2011; Miah \& Rich, 2008). In turn, emphasis is placed on individuals to consume the values and practices disseminated in order to understand and change themselves, and others (Wright, 2009). For example, one can reduce risk factors to serious diseases by adhering to appropriate lifestyle behaviours, such as altering one's diet (Miah \& Rich, 2008). It is here where the health practices related to the body are an 
object of intervention (Williamson, 2014). Assessment of bodies that are perceived to be making lifestyle choices that do not adhere to their responsibilities as good citizens reinforce the ideal of thinness and the association between health and thinness (Wright, 2009). This appears to conform with findings on other visual mechanisms, such as magazines (Schneider \& Davis, 2010), that reinforce the social constructed norms associated with health and the healthy body.

\section{The Present Study}

The present study explores the way in which young females use fitness on SNSs to gather and use health information. We reflect on the emphasis on health as an individual concern through the messages found online, and the notion of 'taking care of oneself' in order to be considered a 'good global citizen' (Edgley \& Brissett, 1990). Furthermore, the view of online fitness culture as a platform for strategies of biopedagogy, and the increasing development of online fitness culture as a tool for self-regulation of the body are highlighted. The present study is motivated by the relative lack of research on the relationship between SNSs and health, more specifically as an aid to gathering health information by textual and visual means (Goodings, 2012).

\section{Method}

The study used a 'blended netnography' (Kozinets, 2010), involving mixing online data collection with offline data collection. The primary researcher conducted a netnography (derived from ethnography, netnography is an online alternative) and individual indepth interviews. This multi-method technique offers triangulation (Berg, 1989) and increased depth of understanding (Creswell \& Plano Clark, 2011; Berg, 1989).

In exploring SNSs, it is important that users' online behaviours such as textual (e.g. comments and posts) and non-verbal (e.g. photographs or videos) are examined. 
Several studies have used similar methods to investigate online communities, termed under a plethora of labels: 'virtual ethnography' (Hine, 2008), online ethnography (Crowe \& Bradford, 2006; Crowe \& Watts, 2014), 'digital ethnography', and 'cyber ethnography' (Grbich, 2007). Netnography (Kozinets, 2010) was selected for use, however, as it provided structured guidelines which follow five steps: research planning, entrée, data collection, interpretation, ensuring ethical standards, and research representation. A rich practice of online community research has used netnographic methods (see Bakardjieva, 2003; Fox \& Roberts, 1999; Kozinets, 2010; Vrooman, 2001). In line with a social constructionist approach, the netnography shaped the scope of the project and assisted in establishing a boundary of thinking, informing interview protocol. The interviews provided an opportunity to explore how online fitness culture is created and experienced and the role that individuals play in creating this culture (Gaskell, 2007). This qualitative, semi-structured approach granted the research an emic epistemological stance (Kottack, 2009), giving priority to the views of participants in online fitness culture in relation to their health knowledge gathering practices. The primary data of this paper is from the individual interviews.

\section{Participants}

After attaining ethics approval, the primary researcher recruited participants through SNSs. This approach to recruitment follows Lamb's (2011) recommendations from an online research project based in the United Kingdom. The researcher created alias Instagram and Facebook accounts in order to access the SNSs to conduct the netnography without the use of a personal profile, a method suited to netnography (Kozinets, 2010). Through these accounts the researcher was able to state the aims of the research, provide an information sheet, dates of data collection and contact information. Participants were purposefully sampled in order to select interviewees who 
met specific criteria related to the use of online fitness. Consistent with the literature reviewed regarding age group and use of SNSs (Sensis, 2014), the characteristics of online health information seekers (Percheski \& Hargittai, 2011; Rice, 2006) and body image concerns (Mission, 2011; Tiggemann \& Slater, 2013), females aged 18 to 24 were invited as participants for this study. In line with homogeneous sampling, participants were required to have a Facebook or Instagram account, and consider themselves a part of the online fitness community. However, the particular community was not defined; it was kept open to encourage an array of participation within the study. As noted by Kozinets (2010), membership within a community is diverse along a 'continuum of participation'. All participants were a part of varying online fitness communities; they each self-identified as online fitness users, and they all had repeat contact, reciprocal familiarity with other users and shared knowledge of some rituals and customs.

Many of the interviews were generated through formal requests for interview (email requests) and further interviewees were contacted through their SNS accounts. While leaving the invitation open to any user of the online fitness community, participants from varying levels of participation e.g. members with a large social network following, to members who were more observers in the community, were included. This ensured that a breadth of experiences and perspectives were represented in the data.

\section{Data collection and analysis}

Twenty-two interviews were conducted, lasting between 35 minutes to over 90 minutes. Interviews took place either in person or via Skype, dependant on geographical location. Each interview was audio-recorded by a voice recorder. The interviews were transcribed verbatim and coded by the first author. Additional member checks were 
conducted by the co-author to ensure accuracy. The transcripts were then coded to ensure confidentiality. This research utilised a thematic analysis approach following Braun and Clarke's (2006). Each transcript was coded to identify meaningful segments of text and interpreted into broader themes. This process culminated in the identification of six principal themes that emerged across the 22 individual interviews.

\section{Results}

Using SNSs can be considered a leisure activity, where one's body is concurrently away from its workday life. However, as Kohn (2007) describes in her experiences, the time that can be classed as 'free time', a person's 'leisure time', is far from free. She explains that there is a strong commitment to work on the body and 'self', challenging popular notions of the definition of 'leisure'. Turner describes leisure as a 'non-work' or an 'anti-work phase' in life, with associated practices absent from leisure practices (1982), although, the idea of 'non-work' has been challenged (Kelly, 1972). Research participants, however, described how their online practices permeate their 'real world' work, inform their knowledge and thoughts and form a strong part of their identity.

\section{Online fitness culture as a source for health information}

Within online fitness culture, a fit or athletic looking body has become a powerful icon for users involved, and a place where this body is consumed. Participants are directed to achieving this ideal through messages that are portrayed within the culture, and consumed by them. Participants described obtaining information on 'health' or 'fitness', often pertaining to diet and exercise. Isla, a participant who used online fitness on SNSs to document her health journey, found information on "food and recipes and stuff, and then gym ideas, and how people do weights at the gym". 
The activities promoted through this information were designed for the masses and advocated that exercise could be done alone or in a group or whenever and wherever (in a gym or not). Accounts often showed exercises that were highly effective for weight loss and body modification (e.g. High intensity interval training), reinforcing the use of exercise in the quest for thinness, and further, the association with thinness and healthiness. The information was conveyed through textual and visual material, which Miah and Rich (2008) refer to as 'performances of health-related information'. This information was gathered by participants viewing different online fitness users' accounts, from eBooks sold through user's accounts, YouTube videos or Instagram videos attached to fitness accounts. Consistent with Vaterlaus et al.'s study (2015), this information was labelled as 'inspirational', and often used as a motivator. It is the immediate, interactive, widespread access to this information, and tailored information that separates this media source from traditional forms of media. This was evident as Niamh, a frequent user and poster within online fitness stated:

It is all so quick and easy. You can just turn up [to exercise] look at your phone and something is going to be up there [on the SNSs newsfeed] about a workout idea, or you can search through hashtags...back in the day if you wanted a gym program you couldn't just jump online and have a look at people's pages and see what the best thing to do is, you actually had to go and speak to a trainer. Whereas these days you can jump onto any social media and get a whole list of anything you can do

All participants found online fitness culture an effective way of sourcing health information, promoting engagement in exercise and a healthy diet, and igniting interest in implementing this information. For example one participant claimed:

I did one [work out] the other day from Paige Hathaway [popular fitness person in online fitness culture]; she was doing some donkey kick thing. I tried to do it and it's so hard! I tried to copy some healthy recipes when I wasn't on this prep 
[currently on body building competition preparation], you can get good information.

The health discourse of neoliberal individual responsibility is deeply entrenched with these online health messages. Often the quotes supporting images online invited individuals to take responsibility for their bodies, working towards the fit or athletic ideal. e.g. "Make yourself fit". These messages ask users to invest in the information provided for body maintenance, in order to perform self-presentation appropriate to the culture (Sassatelli, 2010). It can be considered a matter of personal choice as to whether or not one succeeds in attaining this healthy lifestyle (Miah \& Rich, 2008). This is reflected in an Instagram post:

You, and only you, are responsibility for shaping your health and your body. You decide what your goals are and how hard you fight to stay on track. The decision, the determination and the choice lies within yourself, no one else can do it or want it for you. You create your own destiny. (Posted on Instagram by a 'fitspo' page, seen 19/03/2014)

This focus on individual responsibility extends to the requirement to control body weight and sustain a healthy lifestyle to be considered a good global citizen. The appearance of the body is representative of a morally responsible lifestyle choice, and an individual's lifestyle practices, attitudes, choices and relationship to the good of the rest of society (Wright, 2009). This creates a dichotomy between population groups. For example, with obesity linked to ill health (Crossley, 2004; Julier, 2008), larger body shapes are not widely publicized online and are thus considered an unhealthy population whose health choices link to irresponsible self-management and require governing. Hence, individual responsibility is evident in the presentation of fitness and health issues and the way in which fatness or overweight bodies are shamed in before and after 
or transformation pictures. In turn, this creates a restricted view of what it means to be healthy, potentially limiting the possibilities for certain body shapes and weights.

Although the study often encountered the message, "Be your best you", emphasis was placed on attaining a 'healthy body', visually determined by the fitness community. Through textual and visual communication, the online fitness community construct a health discourse reflective of the association of weight and health and body shape and health, hence with a strong emphasis on appearance orientation. While shifting away from the depiction of thinness may be looked upon in a positive light, physical attractiveness and perfect attributes are still at the centre of the healthy looking ideal. Markula (2001) raises concerns pertaining to this desirable body which potentially commands greater restrictions, for example toned muscles on slender women. Noteworthy, the practices promoted by the online fitness community assume that a user has the capacity to make these imperative choices and act on them, with no acknowledgement of social and cultural determinants. Issues arise as the accessibility to the promoted resources to attain this desired look are not taken into consideration (Mosleh, 2014). A critical consumer of online health information, Charlotte, reflected on this:

People who have their MACCA powder smoothie with spirulina and their chia seeds...this is not attainable for a normal person, like when someone is living in poorer community

Similar messages about diet, exercise and individual responsibility are also evident in the presentation of health in traditional media (Wright, 2009).

\section{Participants' use of SNS practices}

Through the use of SNS practices users of online fitness effectively promote disciplinary and regulatory strategies that advocate certain health behaviours in the 
name of health and life. Users of online fitness act as consumers of this information helped by regulatory strategies that present information as objective and empowering. Site communications (e.g. 'liking', 'sharing' and interacting online) can be viewed as strategies for promoting particular health and body ideals. It is through these social interactions that health messages are circulated, and where users come to identify and confuse popular messages with what is perceived as seemingly "correct". Consistent with previous research (Vaterlaus et al., 2015), participants perceived that viewing some circulated messages led to feelings of motivation, feeling the desire to exercise, or feeling hungry. In the current study, one participant described that 'from seeing popular pictures' within online fitness culture, it showed her 'what to eat to get a flat stomach'.

As evidenced, online fitness culture has the capacity to motivate and encourage healthy living, emphasising 'strength and empowerment' (Tiggemann \& Zaccardo, 2015) through visual and textual messages. By populating news feeds with images of healthy food, fit bodies and video exercises, accompanied by a proliferation of professional and unprofessional advice, the use of hashtags can be viewed as another strategy for consumption of health messages. For example, through the use of the hashtag 'fitspiration', a biopedagogy is created as the health messages circulated act as 'instructions' which direct users to regulate their body by eating healthily and staying active (Wright \& Halse, 2014). These easily accessible messages offer a plethora of information for the consumer to make 'informed' decisions about their health and lifestyle practices, and present repeating messages of responsibility for one's health. While some posts are deliberate attempts to change behaviour or to instruct one about how they should live, such as exercise regimes or diet, others are subtler, for example before and after transformation pictures.

\section{Health Fascism}


Another strategy within online fitness culture is the use of popular status.

Community participants with stated health knowledge and/or credentials (e.g. personal trainers, or athletes), enjoyed a higher value within the community, whereby 'expert knowledge' about health was exchanged for popularity expressed by a large following or 'like' base. For example, popular users drew from apparent educational, professional, and other personal life experiences when interacting with followers, most often to help with fitness journeys, or alleviate any concerns. On Instagram these popular users can be referred to as 'Insta-celebrities'. These popular users urge people to 'work' on their bodies, positioning their followers (or audience) as active agents to adhere to the created truths and standards produced around health and the body (Wright, 2009).

Popular users teach followers how to eat healthily, exercise, and transmit a number of ideals that frame a particular body shape as superior and certain products as desirable or exercises as necessary. They also utilize a range of approaches to teach followers how to maintain self-discipline and stay motivated, how to complete exercises, how to set goals etc. Common techniques used to teach followers these practices were: suggesting they follow people on SNSs who embodied their goal, to choose a diet which worked for them, to exercise with others, to purchase eBooks often designed by the popular person, to sign up for exercise events and to remain regularly involved within the fitness family online through posting images and comments. The seemingly always positive responses on SNSs from followers often positioned the advice received as important and useful, thereby encouraging the self-assessment and self-monitoring of bodies and behaviours against 'norms of appearance and body shape and moral imperatives regarding eating and exercise' (Wright, 2009, p. 10). This further reinforced the disciplining of bodies, urging people to work on themselves. 
Edgley and Brissett's (1990) idea that health is a moral obligation, gives justification to people who wish to intrude into other people's lives who are either 'ignorant', 'unable' or 'unwilling' to act on health (p. 259). This is reflected online with various popular users asserting increasing observation and control over what people do with their bodies and what they put into their bodies with everyone's acts said to 'affect others' (Edgley \& Brissett, 1990, p. 260). This public surveillance, monitoring and regulating of the personal habits of people suspected of not following the socially constructed ideals of the health norm (Carlyon, 1984) can be labelled as 'Health Fascism' (Edgley \& Brissett, 1990, p. 260). Health Fascism is strongly linked to the quest for a 'perfect body' for all (Edgley \& Brissett, 1990). Throughout the past decade, the 'obesity epidemic' has become the most visible target of these Health Fascists or as Edgley and Brissett (1990) term it, 'Health Nazis' (p. 260). Personal characteristics such as laziness, weak will power and defective character are often blamed for the causes of obesity (Gard \& Wright, 2005). Hence, it becomes a moral obligation to ensure that the 'problem' (Edgley \& Brissett, 1990) is fixed and that people attain the perfect body or healthy ideal as perpetuated within online fitness culture. This occurs through the transmission of ideals in online interactions from popular users. Scarlett, a study participant with many online followers, explained the way in which sharing particular images can articulate to her followers the type of idealised body she desires:

If I see a really good picture of a girl's body, I'm going to post it. It's only because I personally feel like that's what I want, that's what I like, and I post it because it inspires me. I know it might not inspire everyone, but the only reason I post it is just to show people what I'm trying to aim for.

Therefore, the understanding of health for users within the online fitness movement is impacted upon by the processes of modelling and discussions around health: 
Alexa: Her [popular online fitness female] page is really bright and colourful. You wake up in the morning and you're like, "Oh, that's really nice. I'm going to get that smoothie that she shared, "cos it's green and it looks cool"

Tess: Look at the example, Adriana and stuff, who are champions and the pros, who are my role models, who I want to be like, they inspire me to work out

In turn, this shapes the health beliefs, norms and constructions around the body, diet, fitness and health. For example, often health messages within online fitness perpetuate healthy as linking to biophysical aspects. Reinforcing this, study participant, Ava, stated that 'being skinny and toned is healthy' as seen through fitness posts. Coinciding with Tiggemann and Zaccardo’s (2015) findings linking to exercise motivated by appearance rather than health, leisure, or enjoyment.

The idea of health online is increasingly being governed by a hybrid mix of popular participants, and advertising companies with business interests. The messages promoting specific diets and active leisure (such as jogging, aerobics, gym work, sport and other purposefully chosen forms of exercise) can be understood as neo-liberal practices implicated in the everyday exercise of power over the self (Markula \& Pringle, 2006). Hence, the promotion of individual leisure and health practices through SNS platforms is a means through which neoliberal discourse is exercised over population groups. By endorsing particular truths about health and healthy living, governing power is formed, inherent in the processes of self-regulation and self-care (Fullagar, 2002; Rose, 1999). Noteworthy, the promoted health messages act as a strategy that is directed towards the body as an object for health, and an object of intervention.

Online fitness culture provides the potential for a 'new' lens through which to view health discourses and for the development of alternative discourses of health (Miah \& Rich, 2008), as well as opportunities for rebellion and resistance (Wright, 
2009). While some body stereotypes are challenged (e.g. female muscularity), the participants do not suggest that dominant discourses are being challenged, irrespective of the potential for these 'safe' spaces and sites to do so (Siibak, 2010). Individuals are encouraged to govern their own healthy lifestyle practices in the name of freedom. This 'freedom' to develop users' own health discourses and identity does not entice them to break the mould as they lapse into dominant health discourses associated with young females. This is echoed by 'healthy ideas' taken as truth. One partitipant, Cienna, stated, "I have heard that whatever the picture is depicting actually works towards getting a healthy body".

In this way, we can see how entrenched health discourses are and the way in which they are globally represented and yet narrowly understood and reconfigured. Hence, SNSs act as another media platform to govern health behaviour as a platform for the development of disciplinary and regulatory strategies. These concepts drawn from analysis strongly link to how online fitness communities persuade users, as individuals, to monitor and regulate themselves and others by 'increasing their knowledge around food and health, and by instructing them on how to change their lives by eating healthy and staying active' (Wright \& Halse, 2014, p. 839).

\section{Conclusion}

This paper examined the way in which health, as an individual responsibility, is perpetuated through key strategies formed within SNSs. To this end, this paper has explored the idea that SNS structures are an emerging form of biopedagogy concerned with governance of the body. These biopedagogies are part of the culture of health fascism and self-management. Qualitative methods were employed to listen to insights from the perspective of young females, given the wealth of data indicating that this population is most susceptible to health issues relating to body aesthetics. Significantly, 
much of this data has focused on analyses of traditional media and its subsequent effects. While there is an emerging understanding of the need to investigate the implications of SNSs, Goodings (2012), suggests that more attention needs to be paid to research looking at the combination of the textual and visual. Furthermore, Vaterlaus et al., (2015) suggest future research to explore the influence of social media on young adult health behaviours.

Dworkin and Wachs (2009) present the idea that a fit body is synonymous with 'good' health, which is often perpetuated by strategies of biopedagogy within fitness magazines. Through the development of Facebook and Instagram, it is evident that online fitness culture also uses strategies of biopedagogy to express health ideas and ideals. The ideas and ideals reproduced and transmitted by users within the culture act as regulatory strategies, values and practices to govern bodies in the name of health (Wright, 2009). Where fitness magazines are printed monthly, SNSs provide a platform for immediate transmission of constructions of ideals, such as health and healthy bodies. It is evident that SNSs have the capacity to act as a platform for informal dissemination of health information to a broad audience. Health professionals have been encouraged to use SNSs to share quality information about health topics to the public (Robillard, Johnson, Hennessey, Beattie, \& Illes, 2013). Previous evaluations of formal health interventions implemented using SNSs have had slight benefits (Williams, Hamm, Shulhan, Vandermeer, \& Hartling, 2014). Significantly, Laranjo et al. (2015) found a positive effect from SNS interventions on health-behaviour outcomes, although considerable heterogeneity was noted. However, researchers have raised concerns regarding the integrity of health information presented online (Brodie et al., 2000; Ettel et al., 2012), or misinformation being given and received in a highly unregulated environment (Hallows, 2013; Jordan, Buchbinder, \& Osborne, 2010). Users of online 
fitness notably require further critical analytical skills relevant to eHealth literacy. The online population should be aware of the bias of some online accounts, and the fact that some sources of information spreading are paid by private groups to pursue commercial interests. In practice users should be able to critically analyse how the information is created, by whom and for what purpose, denoting the interests behind this information. As the onus of good health is placed primarily on the individual, this study raises issues over the ability to achieve eHealth literacy in order to distinguish accurate facts from misleading information, which is at times transmitted by numerous SNSs users. Regulations on SNS content may potentially ensure that the generation and distribution of health information is valid and non-biased. This may allow strength in SNS health interventions and communications. However, we are aware that regulating information is a controversial matter. Further study is warranted to explore how SNSs and other online platforms may provide a venue to disseminate credible health information and promote positive behaviour change.

Noting participants' admittance to passing judgment on other's health status based on aesthetics, the findings from this research suggest that more work may need to be done to promote the idea that healthy can be embodied in diverse shapes and sizes. Adding to this, Bordo (2003) argues that there is an 'institutionalized system of values and practices within which girls and women (and, increasingly, boys and men as well) come to believe they are nothing (and frequently treated as nothing) unless they are trim, tight, lineless, bulgeless, and sagless' (p.32). This is an area of concern, which can be brought to attention through education around the societal construction of health, and through body image acceptance. Education has the capacity to challenge the messages of biopedagogies either within a formal or informal setting. Education may also address the need for positive health promotion discourses in talking about the use of leisure time 
and health and critical analytical skills required for SNS practices. This paper adds to the literature about work on the body and work and leisure as a single domain within leisure (Kohn, 2007; Waring, 2008).

1. All participants have been given pseudonyms.

2. Trivial words have been omitted from participant quotations

Acknowledgements:

Thank you to all of the interviewees who shared their stories and experiences. Without their consent, this research would not have been possible. Thank you to the two anonymous reviewers for their suggestions, comments and insightful feedback. Thank you also to Andrew Craig for providing valuable support during this process. 


\section{References}

Amit, V., \& Rapport, N. (2002). The Trouble with Community: Anthropological Reflections on Movement, Identity and Collectively. London: Pluto.

Andreasson, J., \& Johansson, T. (2013a). Female Fitness in the Blogospere: Gender, Health, and the Body. SAGE Open. doi: 10.1177/2158244013497728

Andreasson, J., \& Johansson, T. (2013c). The Health Guru. Masculinity and fitness coaching in the blogosphere. The Journal of Men's Studies, 21(3), 277-290.

Australian Bureau of Statistics. (2012). Children's Participation in Cultural and Leisure Activities. (4901.0).

http://www.abs.gov.au/ausstats/abs@.nsf/Latestproducts/4901.0Main\%20Featur es7Apr\%202012? opendocument\&tabname $=$ Summary\&prodno $=4901.0 \&$ issue $=$ Apr\%202012\&num=\&view: Australian Bureau of Statistics.

Bakardjieva, M. (2003). Virtual Togetherness: An Every-day Life Perspective. Media, Culture \& Society, 25(3), 291-313.

Bardone-Cone, A. M., \& Cass, K. M. (2007). What does viewing a pro-anorexia website do? An experimental examination of website exposure and moderating effects. Int J Eat Disord, 40(6), 537-548. doi: 10.1002/eat.20396

Berkman, N. D., Davis, T. C., \& McCormack, L. (2010). Health Literacy: What Is It? Journal of Health Communication, 15(sup2), 9-19. doi: $10.1080 / 10810730.2010 .499985$

Boepple, L., \& Thompson, J. K. (2015). A content analytic comparison of fitspiration and thinspiration websites. Int J Eat Disord. doi: 10.1002/eat.22403

Bordo, S. (2003). Unbearable Weight: Feminism, Western Culture, and the Body. (10th Anniversary ed.). London: University of California: Press.

Borzekowski, D. L., Schenk, S., Wilson, J. L., \& Peebles, R. (2010). e-Ana and e-Mia: A content analysis of pro-eating disorder Web sites. Am J Public Health, 100(8), 1526-1534. doi: 10.2105/AJPH.2009.172700

Braun, V., \& Clarke, V. (2006). Using thematic analysis in psychology. Qualitative Research in Psychology, 3(2), 77-101. doi: 10.1191/1478088706qp063oa

Brodie, M., Flournoy, R. E., Altman, D. E., Blendon, R. J., Benson, J. M., \& Rosenbaum, M. D. (2000). Health information, the Internet, and the digital divide. Health Affairs, 19(6), 255-265. doi: 10.1377/hlthaff.19.6.255

Brotsky, S. R., \& Giles, D. (2007). Inside the "pro-ana" community: a covert online participant observation. Eat Disord, 15(2), 93-109. doi: 10.1080/10640260701190600

Buchanan, H., \& Coulson, N. (2007). Accessing dental anxiety online support groups: An exploratory qualitative study of motives and experiences. Patient Education and Counseling, 66(3), 263-269.

Camerini, L., Diviani, N., \& Tardini, S. (2010). Health virtual communities: is the Self lost in the Net? Social Semiotics, 20(1), 87-102. doi: 10.1080/10350330903507230

Carlyon, W. H. (1984). Disease Prevention/Health Promotion: Briding the Gap to Wellness. Health Values: Achieving High Level Wellness, 8(3), 27-30.

Cline, R. J. W., \& Haynes, K. M. (2001). Consumer health information seeking on the Internet: the state of the art. Health Education Research, 16(6), 671-692.

Coulson, N., Buchanan, H., \& Aubeeluck, A. (2007). Social support in cyberspace: a content analysis of communication within a Huntington's disease online support group. Patient Educ Couns, 68(2), 173-178. doi: 10.1016/j.pec.2007.06.002 
Coulson, N., \& Knibb, R. (2007). Coping with food allergy: Exploring the role of the online support group. CyberPsychology and Behavior, 10(1), 145-148. doi: $10.1089 / \mathrm{cpb} .2006 .9978$

Crossley, N. (2004). Fat is a Sociological Issue: Obesity Rates in Late Modern, 'BodyConscious' Societies. Social Theory \&\#38; Health, 2(3), 222-253. doi: 10.1057/palgrave.sth.8700030

Crowe, N., \& Bradford, S. (2006). 'Hanging out in Runescape': Identity, Work and Leisure in the Virtual Playground. Children's Geographies, 4(3), 331-346. doi: $10.1080 / 14733280601005740$

Crowe, N., \& Watts, M. (2014). 'We're just like Gok, but in reverse': Ana Girls empowerment and resistance in digital communities. International Journal of Adolescence and Youth, 1-12. doi: 10.1080/02673843.2013.856802

Cullen, R. (2006). Health information on the Internet: A study of providers, quality, and users. Westport: Praeger Publishers.

Dutta-Bergman, M. J. (2004). Primary sources of health information: comparisons in the domain of health attitudes, health cognitions, and health behaviors. Health Communication, 16(3), 273-288. doi: 10.1207/S15327027HC1603_1

Dworkin, S., \& Wachs, F. (2009). Body Panic: Gender, Health, and the Selling of Fitness. New York: New York University Press.

Edgley, C., \& Brissett, D. (1990). Health Nazis and the Cult of the Perfect Body: Some Polemical Observations. Symbolic Interaction, 13(2), 257-279. doi: 10.1525/si.1990.13.2.257

Ettel, G., Nathanson, I., Ettel, D., Wilson, C., \& Meola, P. (2012). How do adolescents access health information? And do they ask their physicians? The Permanente Journal, 16(1).

Feng, Y., \& Xie, W. (2015). Digital divide 2.0: the role of social networking sites in seeking health information online from a longitudinal perspective. $J$ Health Commun, 20(1), 60-68. doi: 10.1080/10810730.2014.906522

Fox, N., \& Roberts, C. (1999). GPs in Cyberspace: the Sociology of 'Virtual Community'. . The Sociological Review, 47(4), 643-671.

Fullagar, S. (2002). Governing the healthy body: Discourses of leisure and lifestyle within Australian health policy. Health: An Interdisciplinary Journal for the Social Study of Health, Illness and Medicine, 6(1), 69-84.

Gard, M., \& Wright, J. (2005). The Obesity Epidemic. Science, morality and ideology. USA \& Canada: Routledge.

Ghaznavi, J., \& Taylor, L. D. (2015). Bones, body parts, and sex appeal: An analysis of \#thinspiration images on popular social media. Body Image, 14, 54-61. doi: 10.1016/j.bodyim.2015.03.006

Goodings, L. (2012). Understanding social network sites: lessons from MySpace. Visual Communication, 11(4), 485-510. doi: 10.1177/1470357212454098

Gray, N. J., Klein, J. D., Noyce, P. R., Sesselberg, T. S., \& Cantrill, J. A. (2005). Health information-seeking behaviour in adolescence: the place of the internet. Social Science \& Medicine, 60(7), 1467-1478. doi: 10.1016/j.socscimed.2004.08.010

Grbich, C. (2007). Qualitative data analysis. An introduction. London EC1Y: SAGE Publications Ltd.

Groesz, M., Levine, M. P., \& Murnen, K. (2002). The Effect of Experimental Presentation of Thin Media Images on Body Satisfaction: A meta-Analytic Review. International Journal of Eating Disorders, 31(1), 1-16. doi: 10.1002/eat.10005 
Hallows, K. M. (2013). Health Information Literacy and the Elderly: Has the Internet Had an Impact? The Serials Librarian, 65(1), 39-55. doi: 10.1080/0361526x.2013.781978

Hargreaves, D., \& Tiggemann, M. (2003). The effect of "thin ideal" television commercials on body dissatisfaction and schema activation during early adolescence. Journal of Youth and Adolescence, 32(5), 367-373. doi: 00472891/03/1000-0367/0

Harper, K., Sperry, S., \& Thompson, J. K. (2008). Viewership of pro-eating disorder websites: association with body image and eating disturbances. Int J Eat Disord, 41(1), 92-95. doi: 10.1002/eat.20408

Hesse, B. W., \& Shneiderman, B. (2007). eHealth research from the user's perspective. Am J Prev Med, 32(5 Suppl), S97-103. doi: 10.1016/j.amepre.2007.01.019

Hine, C. (2008). The Internet and Research Methods. In N. Gilbert (Ed.), Researching Social Life (3rd ed., pp. 304-320). London EC1Y: SAGE Publications Ltd

Iriart, C., Franco, T., \& Merhy, E. E. (2011). The creation of the health consumer: challenges on health sector regulation after managed care era. Global Health, 7, 2. doi: 10.1186/1744-8603-7-2

Jordan, J. E., Buchbinder, R., \& Osborne, R. H. (2010). Conceptualising health literacy from the patient perspective. Patient Education and Counseling, 79(1), 36-42. doi: 10.1016/j.pec.2009.10.001

Julier, A. (2008). The Political Economy of Obesity: The Fat Pay All. In C. Counihan \& P. V. Esterik (Eds.), Food and culture: A reader (pp. 484-499). New York, London: Routledge.

K-fig. (2011). Fitspiration. from http://www.urbandictionary.com/define.php?term=fitspiration

Kaplan, A. M., \& Haenlein, M. (2010). Users of the world, unite! The challenges and opportunities of Social Media. Business Horizons, 53(1), 59-68. doi: 10.1016/j.bushor.2009.09.003

Kelly, J. R. (1972). Work and leisure: A simplified paradigm. Journal of Leisure Research, 4(1), 50-62.

Kerner, M. S. (2005). Leisure-Time Physical Activity, Sedentary Behavior, and Physical Fitness among Adolescents. Journal of Physical Education, Recreation \& Dance, 76(8), 26-30. doi: 10.1080/07303084.2005.10608294

Kohn, T. (2007). Bowing onto the Mat: Discourses of Change Through Martial Arts Practice. In S. Coleman \& T. Kohn (Eds.), The Discipline of Leisure: Embodying Cultures of 'Recreation'. United States: Berghahn Books.

Kottack, P. C. (2009). Mirror for Humanity. A Concise Introduction to Cultural Anthropology (7th ed.). New York: McGraw-Hill.

Kozinets, R. (2010). Netnography. Doing Ethnographic Research Online. London EC1Y: SAGE Pulications Ltd.

Kozinets, R. (2015). Netnography: Redefined (2nd ed.). London: SAGE Publications Ltd.

Lamb, R. (2011). Facebook Recruitment. Research Ethics, 7(2), 72-73. doi: $10.1177 / 174701611100700208$

Laranjo, L., Arguel, A., Neves, A. L., Gallagher, A. M., Kaplan, R., Mortimer, N., . . . Lau, A. Y. (2015). The influence of social networking sites on health behavior change: a systematic review and meta-analysis. J Am Med Inform Assoc, 22(1), 243-256. doi: 10.1136/amiajnl-2014-002841

Levy, P. (2001). Cyberculture (t. b. R. Bononno Ed.). Minneapolis, MN: University of Minnesota Press. 
Markula, P. (2001). Firm but Shapely, Fit but Sexy, Strong but Thin: The Postmodern Aerobicizing Female Bodies. In J. R. Johnston (Ed.), The American Body in Context. An Anthology. USA: Scholarly Resources Inc.

Markula, P., \& Pringle, R. (2006). Foucault, Sport and Exercise. Power, knowledge and transforming the self. London and New York: Routledge.

McFerran, B., Dahl, D. W., Fitzsimons, G. J., \& Morales, A. C. (2010). I'll Have What She's Having: Effects of Social Influence and Body Type on the Food Choices of Others. Journal of Consumer Research, 36, 915-929.

Mcmillan, S. J., \& Morrison, M. (2006). Coming of age with the Internet: A qualitative exploration of how the Internet has become an integral part of young people's lives. New Media and Society., 8(1), 73-95. doi: 10.1177/1461444806059871

Meyers, E. A. (2012). 'Blogs give regular people the chance to talk back': Rethinking 'professional' media hierarchies in new media. New Media \& Society, 14(6), 1022-1038. doi: 10.1177/1461444812439052

Miah, A., \& Rich, E. (2008). The Medicalization of Cyberspace. Oxon, USA, Canada: Routledge.

Mission, A. (2011). National survey of young Australians 2011. Key and emerging issues: young people.

Mosleh, D. (2014). The Biomedical and Holistic Practices of the Continuum of Healthism. Major Research Papers, 2.

Murero, M., D'Ancona, G., \& Karamanoukian, H. (2001). Use of the Internet by patients before and after cardiac surgery: telephone survey. Journal of Medical Internet Research, 3(3), e27.

Oh, H. J., Lauckner, C., Boehmer, J., Fewins-Bliss, R., \& Li, K. (2013). Facebooking for health: An examination into the solicitation and effects of health-related social support on social networking sites. Computers in Human Behavior, 29(5), 2072-2080. doi: 10.1016/j.chb.2013.04.017

Percheski, C., \& Hargittai, E. (2011). Health information-seeking in the digital age. $J$ Am Coll Health, 59(5), 379-386. doi: 10.1080/07448481.2010.513406

Peterson, G., Aslani, P., \& Williams, K. A. (2003). How do Consumers Search for and Appraise Information on Medicines on the Internet? A Qualitative Study Using Focus Groups. Journal of Medical Internet Research, 5(4), e33. doi: 10.2196/jmir.5.4.e33

Rice, R. E. (2006). Influences, usage, and outcomes of Internet health information searching: multivariate results from the Pew surveys. Int J Med Inform, 75(1), 828. doi: 10.1016/j.ijmedinf.2005.07.032

Rice, R. E., \& Katz, J. E. (Eds.). (2001). The Internet and Health Communication. Thousand Oaks, CA: Sage.

Robillard, J. M., Johnson, T. W., Hennessey, C., Beattie, B. L., \& Illes, J. (2013). Aging 2.0: health information about dementia on Twitter. PLoS One, 8(7), e69861. doi: 10.1371/journal.pone.0069861

Rose, N. (1999). Powers of Freedom: Reframing Political Thought. Cambridge, UK: Cambridge University Press.

Sassatelli, R. (2010). Fitness Culture. Gyms and the Commercialisation of Discipline and Fun. ebook: Basingstoke Palgrave Macmillan.

Schneider, T., \& Davis, T. (2010). Fostering a hunger for health:Food and the self in 'The Australian Women's Weekly'. Health Sociology Review, 19(3), 285-303.

Sensis. (2014). Yellow Social Media Report 2014. What Australian people and businesses are doing with social media. Australia. 
Siibak, A. (2010). Constructing masculinity on a social networking site: The case-study of visual self-presentations of young men on the profile images of SNS Rate. Young, 18(4), 403-425. doi: 10.1177/110330881001800403

Smith, A. C. T., \& Stewart, B. (2012). Body Perceptions and Health Behaviors in an Online Bodybuilding Community. Qualitative Health Research, 22(7), 971-985. doi: $10.1177 / 1049732312443425$

Strelan, P., Mehaffey, S. J., \& Tiggemann, M. (2003). Self-Objectification and Esteem in Young Women: The Mediating Role of Reasons for Exercise. Sex Roles, 48(1/2), 89-95.

Szabo, A. (2003). The acute effects of humor and exercise on mood and anxiety. Journal of Leisure Research, 35(2), 152-162.

Tardy, R. W., \& Hale, C. L. (1998). Getting "plugged in": A network analysis of healthinformation seeking among "stay-at-home moms". Communication Monographs, 65(4), 336-357. doi: 10.1080/03637759809376457

Tiggemann, M., \& Slater, A. (2013). NetGirls: The Internet, Facebook, and body image concern in adolescent girls. International Journal of Eating Disorders, 46(6), 630-633. doi: 10.1002/eat.22141

Tiggemann, M., \& Zaccardo, M. (2015). "Exercise to be fit, not skinny": The effect of fitspiration imagery on women's body image. Body Image, 15, 61-67. doi: 10.1016/j.bodyim.2015.06.003

Toseeb, U., \& Inkster, B. (2015). Online social networking sites and mental health research. Front Psychiatry, 6, 36. doi: 10.3389/fpsyt.2015.00036

Turner, J. (1982). Towards a cognitive redefinition of the social group. In H. Tajfel (Ed.), Social Identity and Inter-Group Relations (pp. 15-40). London: Academic Press.

Vaterlaus, J. M., Patten, E. V., Roche, C., \& Young, J. A. (2015). \#Gettinghealthy: The perceived influence of social media on young adult health behaviors. Computers in Human Behavior, 45. doi: 10.1016/j.chb.2014.12.013

Velardo, S., \& Drummond, M. J. N. (2013). Understanding parental health literacy and food related parenting practices. Health Sociology Review, 22(2), 137-150.

Vrooman, S. S. (2001). Flamethrowers, Slashers, and Witches: gendered Communication in a Virtual Community. Qualitative Research Reports in Communication, 33-41.

Waring, A. (2008). Health club use and 'lifestyle': exploring the boundaries between work and leisure. Leisure Studies, 27(3), 295-309. doi: 10.1080/02614360802048845

Welbourne, J. L., Blanchard, A. L., \& Wadsworth, M. B. (2013). Motivations in virtual health communities and their relationship to community, connectedness and stress. Computers in Human Behavior, 29(1), 129-139. doi: 10.1016/j.chb.2012.07.024

Williams, G., Hamm, M. P., Shulhan, J., Vandermeer, B., \& Hartling, L. (2014). Social media interventions for diet and exercise behaviours: A sustematic review and meta-analysis of randomised controlled trials. BMJ Open, 4(e003926). doi: 10.1136/bmjopen-2013003926

Williamson, B. (2014). Algorithmic skin: health-tracking technologies, personal analytics and the biopedagogies of digitized health and physical education. Sport, Education and Society, 20(1), 133-151. doi: $10.1080 / 13573322.2014 .962494$ 
Wright, J. (2009). Biopower, Biopedagogies and the obesity epidemic. In J. Wright \& V. Harwood (Eds.), Biopolitics and the 'Obesity Epidemic': Governing Bodies (pp. 1-14). New York: Routledge.

Wright, J., \& Halse, C. (2014). The healthy child citizen: Biopedagogies and web-based health promotion. British Journal of Sociology of Education, 35(6), 837-855. 